Case Reports

\title{
Chromomycosis: Case Reports of Exuberant Forms Including Carcinomatous Degeneration
}

\author{
${ }^{1,2}$ Carla Andréa Avelar Pires, ${ }^{3}$ Aline de Lima Dias, ${ }^{1}$ Adriana Kamilly Leitão Pitman Machado, \\ ${ }^{2}$ Manuela Nascimento de Lemos, ${ }^{1}$ Walter Refkalefsky Loureiro and ${ }^{1}$ Francisca Regina Oliveira Carneiro \\ ${ }^{1}$ Department of Dermatology, Universidade do Estado do Pará, Belém, Pará, Brazil \\ ${ }^{2}$ Department of Medical Habilities, Universidade Federal do Pará, Brazil \\ ${ }^{3}$ Department of Dermatology, Centro Universitário do Estado do Pará, Belém, Pará, Brazil
}

Article history

Received: 26-12-2018

Revised: 25-01-2019

Accepted: 04-02-2019

Corresponding Author: Carla Avelar Pires Department of Dermatology, Universidade do Estado do Pará, Belém, Pará, Brazil Email: carlaavelarpires@gmail.com

\begin{abstract}
Chromomycosis, or chromomycosis, is a chronic, progressive cutaneous and subcutaneous mycosis caused by several species of pheoid or dermaticeous (darkly pigmented) fungi. It mainly affects male patients, in the age group between 30 and 60 years and is more common on rural areas, being associated to traumatic events, which may explain the high frequency of involvement of the lower limbs and exposed areas. Its lesion starts as a small, nonpruriginous, erythematous papule or macula and slowly spreads to the surrounding skin. Commonly, takes 5 to 15 years or more from the onset to diagnosis the disease. The disease progress and evolve to variable morphology types, chronic lesions and complications usually lead to definitive disability, especially due to treatment limitations. We present three cases of exuberant and disfiguring chromomycosis, including a case were the lesions suffered carcinomatous degeneration. All patients complained about the drug price and one of them abandoned the treatment and medical follow up. All patients were from rural area, one of them complained about the absence of medication and reported financial difficulties for transportation. In conclusion, physicians must be aware of chromomycosis as a possible diagnosis when considering a chronic skin condition. Although not common, prevention strategies and alternative therapies should be investigated to improve chromomycosis management, especially in undeveloped regions. The distance and difficulties to accesses health services may delay the diagnosis and prejudice the treatment, given that small and initial lesions have better prognosis, impairing the improvement in patients' quality of live and the prevention of severe complications and morbidities.
\end{abstract}

Keywords: Chromomycosis, Dermatomycosis, Antifungal Agents, Rural Population, Socioeconomic Factors, Low-Income Population

\section{Introdation}

Chromomycosis (CBM) is a chronic deep mycosis that may lead to severe morbidity, causing disfiguration and disability (Queiroz-Telles, 2015; Lupi et al., 2005). The highest prevalence rates reported are within the most of the tropical and subtropical zone, being most cases reported in Madagascar, South Africa, Brazil and Costa Rica (QueirozTelles, 2015; Queiroz-Telles et al., 2011; Deng et al., 2015). However, autochthone cases and different agents strains have been identified in Europe and other zones (Deng et al., 2015; Pindycka-Piaszczyńska et al., 2014). The infection is more prevalent in males $30-50$ years of age engaged in agriculture (70\% of cases) (Bonifaz et al., 2001; Attapattu, 1997). In Madagascar, 87\% of patients with CBM are males above 16 years of age (Esterre et al., 1997). Minotto et al. (2001) observed in their study the 4: 1 maleto-female incidence ratio in Brazil. Moreover, the disease is most prevalent in farmers (aged 50-60) (Brasil da, 2016). It is explained by a more frequent engagement of males in agricultural activities in those countries, which increases the possibility of injury with parts of plants affected by fungi responsible for this disease (Krzyściak et al., 2014).

It is considered an occupational disease, occurring more frequently on rural areas and associated to trauma in plants 
or soil (Queiroz-Telles et al., 2011). For this reason, it is more frequent on the legs and other exposed areas and rare in children (Queiroz-Telles, 2015; Torres-Guerrero et al., 2012). The lesions start as a small macule or papule and progress over months or years to polymorphic plaques, or vegetatives lesions, with or without scales or ulceration (Queiroz-Telles, 2015; Torres-Guerrero et al., 2012).

The diagnosis can be performed by direct examination with potassium hydroxide $(\mathrm{KOH})$, biopsy or culture. A characteristic finding is the presence of muriform cells or sclerotic bodies, which are doublewalled brown structures that can be identified with haematoxylin and eosin, without special stains on histopathology (Lupi et al., 2005; Queiroz-Telles et al., 2011; Torres-Guerrero et al., 2012).

The treatment is still a challenge to clinicians and patients, due to the chronic involvement of cutaneous and subcutaneous tissue with recalcitrant lesions that are caused by a fungus, resulting in a slowly and poor response (Queiroz-Telles, 2015; Lupi et al., 2005; TorresGuerrero et al., 2012). The surgical removal can be done for small initial lesions (Queiroz-Telles, 2015; Lupi et al., 2005; Torres-Guerrero et al., 2012); an open comparative trial showed that topical Ajoene and 5-fluorouracil can be used as therapeutic alternative for localized chromomycosis ( $\leq 2.5 \mathrm{~cm}$ diameter) (Pe'Rez-Blanco et al., 2003); another trial suggested that cryosurgery would be the best choice for small lesions ( $\leq 15 \mathrm{~cm}^{2}$ in area) and Itraconazole (ITZ) indicated for lesions in the flexures, in whom cryotherapy is contraindicated or for large lesions to reduce the size, to then use cryosurgery (Alexandro et al., 1997). Other therapeutic alternatives are reported in some cases, as combinations of Terbinafine, Itraconazole, 5-fluorouracil, 5-fluorocytosine and/or oral amphotericin B and local heat (Queiroz-Telles, 2015; Lupi et al., 2005).
Despite of commonly frequent in rural areas, chromomycosis lacks epidemic potential. The most recent epidemiological data reported the occurrence of 65 cases in seven years in the State of Pará, Brazil (Pires et al., 2012). As we are aware, there is no systematic review or even randomized controlled trials about it, almost every data about chromomycosis comes from observational studies (Queiroz-Telles, 2015; Lupi et al., 2005; Queiroz-Telles et al., 2011).

To contribute to the knowledge of the disease, this study aimed to describe two exuberant cases of chromomycosis detailing the clinical features, diagnosis and management of the patients. Although this is a case report, it will provide valuable information about this not common disease and its rare exuberant form and provide a useful start point to discuss the difficulties and social disparity influence in its management, in order to prioritise prevention strategies and therapeutic alternatives.

\section{Case Report 1}

A 58-year-old brown man was admitted in the dermatological service in September, 2014 with irregular vegetant plaques with hypochromic and erythematous areas on half of the thigh and on the superior $2 / 3$ of the right leg. There was areas discharging pus and with a bad smell (Fig. 1).

The patient was a farmer, living in a rural area of Acará city, a small island in the State of Pará in Brazil, far away from the capital. He described the arising of verrucous lesions with progressive growth on the right leg 20 years ago. The patient denied any oral or topic treatment and previous comorbidities.

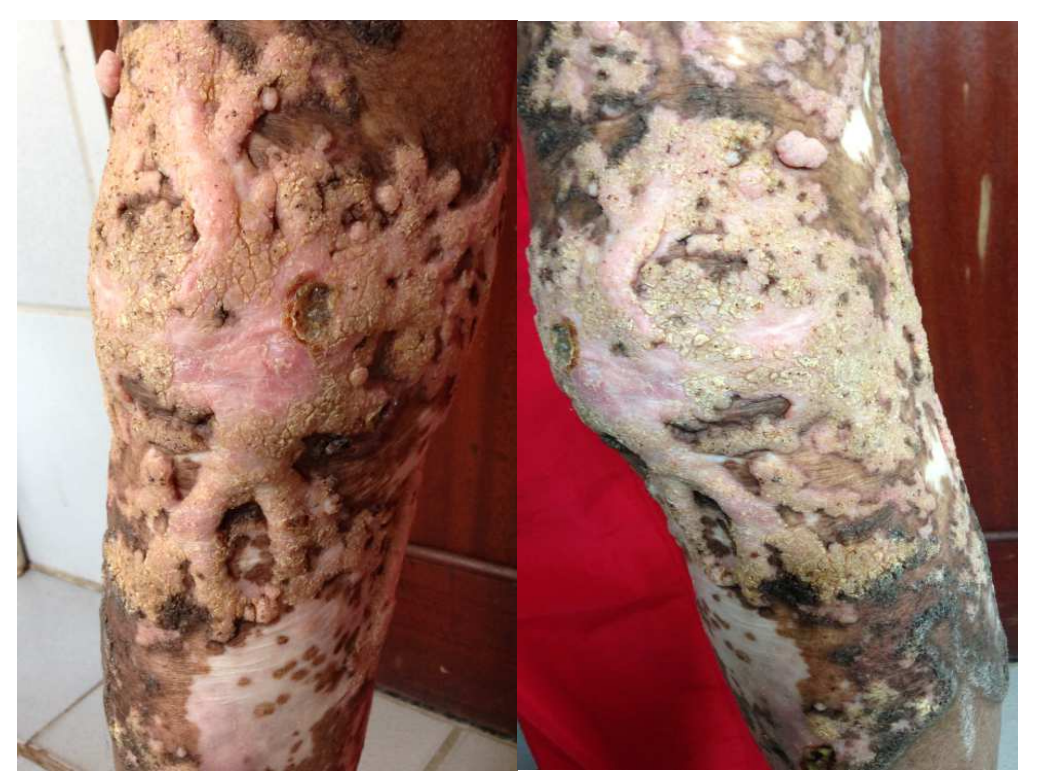

Fig. 1: Irregular vegetant plaques with hypochromic and erythematous areas on half of the thigh and on the superior $2 / 3$ of the right leg 

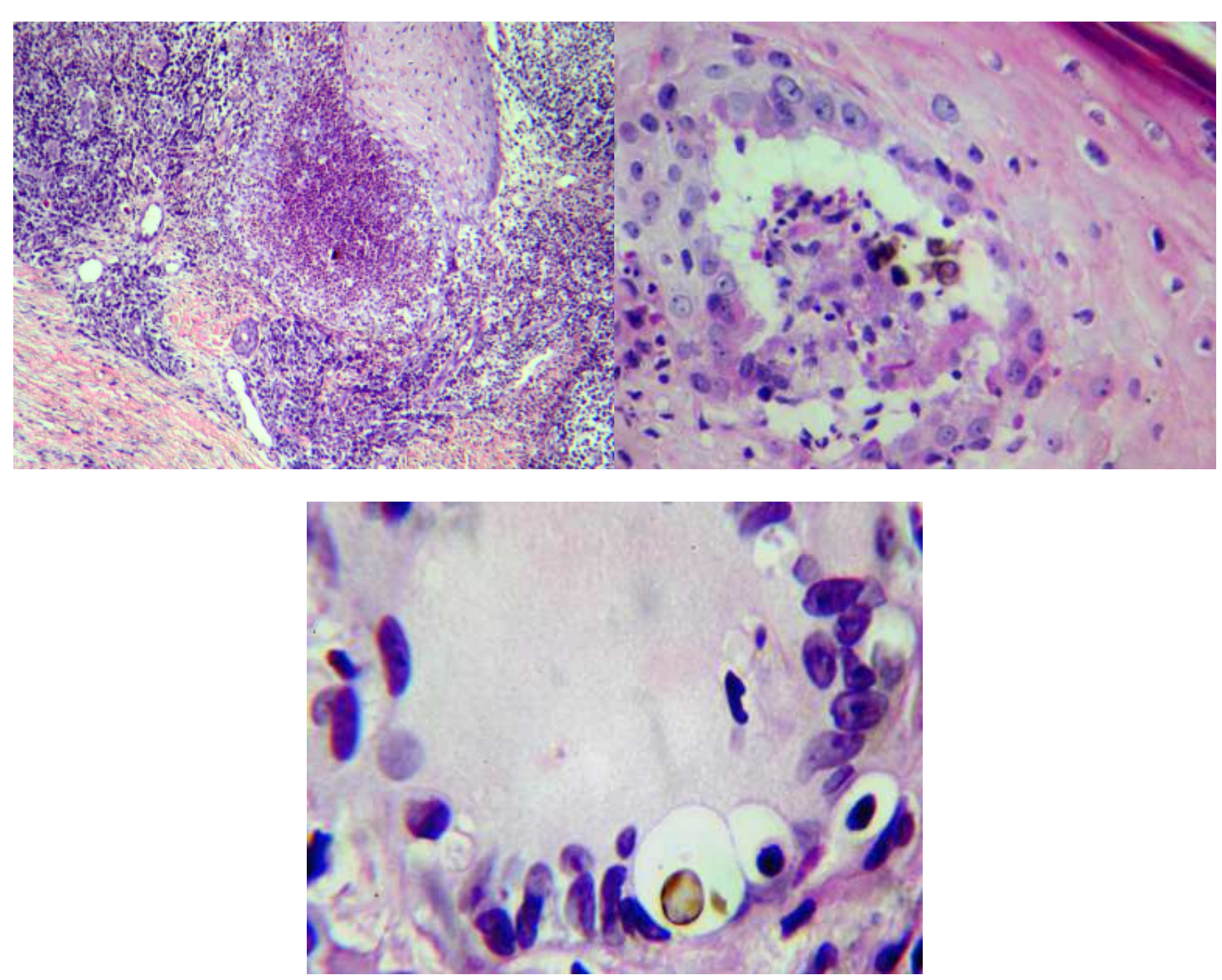

Fig. 2: Histopathology showing chromomycosis lesions

After anamnesis and physical examination, the patient was diagnosed with a secondary infection of the lesion and a biopsy was required to confirm the chromomycosis diagnosis. We also performed a direct mycological examination. Itraconazole $200 \mathrm{mg}$ /day was prescribed.

The patient returned in December, 2014 referring an improvement of the lesions, but complaining about the Itraconazole price. The plaque was still discharging pus. The histopathology demonstrated a thinned epidermis. At the dermal level there were an abundant lymphoplasmhistiocytic inflammatory infiltrate, granuloma cells with epithelioid cells and multinucleated giant cells differentiation, foreign body-type cells, polymorphonuclear neutrophils and eosinophils, with eosinophils abscess formation. There were also the presence of several fungal structures naturally brown pigmented under the form of spores (muriform cells) (Fig. 2). Itraconazole was maintained. Secondary infections were treated with antibiotics whenever necessary.

The patient has not returned until today, despite our efforts to contact him. This evasion of medical treatment may be explained because of low financial conditions and difficulties to acess waterway transportation.

\section{Case Report 2}

A 49-year-old brown man was admitted in the dermatological service in November, 2013 with irregular verrucous plaques with black dots and erythematous areas on the left foot and tibiae-tarsal region (Fig. 3).

The patient was a farmer, living in a rural area of Magalhães Barata city, a small town in the State of Pará, Brazil. He described the arising of nonpruriginous erythematous papules on the left leg, which slowly spread and turned into these verrucous plaques, measuring about 20 centimetres in its larger axis, after a leg injury 10 years ago. The patient denied any oral or topic treatment and previous comorbidities.

After anamnesis and physical examination, a biopsy was required to confirm the chromomycosis diagnosis. Itraconazole $200 \mathrm{mg}$ /day was prescribed, because of extensive lesions. The direct examination demonstrated fumagoid cells (Fig. 4). Biopsy and direct mycological examination confirmed chromomycosis diagnosis.

In August, 2014 after regular following with laboratorial exams and prescription of Itraconazole, the patient returned referring an improvement of the lesion, but without taking 
the medication for 2 months. In physical examination, it was noticed that the plaque grown, extending now from the left foot to the distal portion of tibiae. The conduct was maintained and exams were solicited.

The patient only returned on April, 2015 and was still not taking the medication. In August, 2015, after 3 not consecutive months of medication, the patient referred local itch and no improvement of the lesion. Secondary infections were treated with antibiotics whenever necessary. In October, 2015 the patient complained about the difficulty of getting the medication on the public health service, so he failed to take the medication. The lesion was with hematic points and bad smell and was extending from the left foot to the thigh. Itraconazole was maintained in $400 \mathrm{mg}$ /day dose.

In May, 2016 the patient returned and was without medication, he missed the previous consultations due to lack of transport. The lesion was presenting bad smell, occupying all left leg, extending from the thigh root to the foot and with intense itch. Ciprofloxacin 500mg for 14 days was prescribed. A judicial order was initiated in June, 2016 to get Itraconazole from the health secretary by the public health system due to the financial conditions of the patient. In the end of 2018, patient returned and was takin the medication. On this occasion, he had not secondary infection and pruritus has ended.

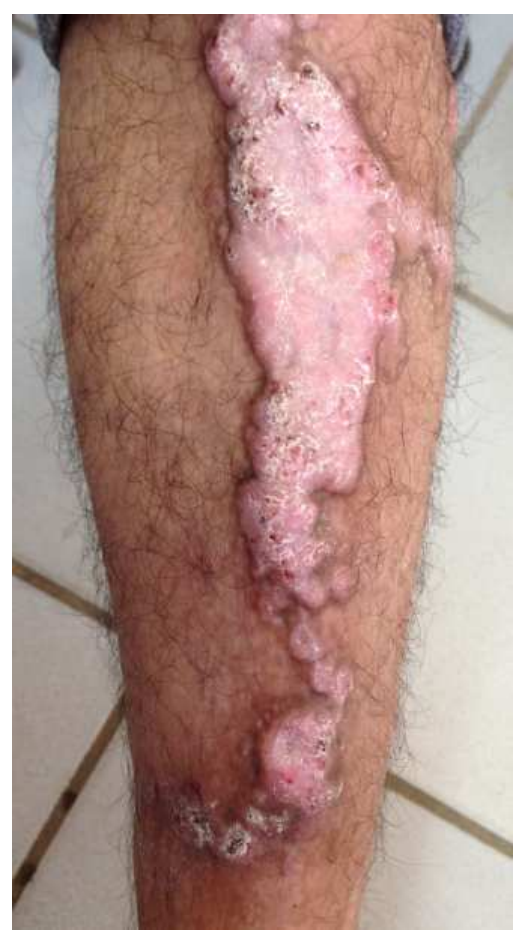

Fig. 3: Irregular verrucous plaques with black dots and erythematous areas on the tibiae-tarsal region

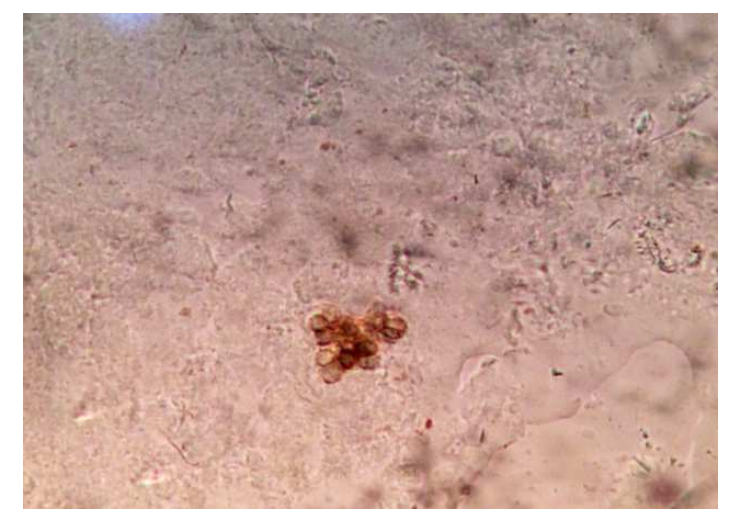

Fig. 4: Fumagoid cells in direct mycological examination 


\section{Case Report 3}

A 55-year-old brown man was admitted in the dermatological service in january, 2012. He had been diagnosed with chromomycosis in 2008. At that moment, he had verrucous plaques in both legs, the biggest one had about $10 \times 8$ centimetres and was located in the right leg. He was takin itraconazole $200 \mathrm{mg} /$ day. The patient was a farmer, living in a rural area of Vigia, in the State of Pará, Brazil. After anamnesis and physical examination, a biopsy was required to confirm the chromomycosis diagnosis. Itraconazole $200 \mathrm{mg}$ /day was maintained. Secondary infections were treated with antibiotics whenever necessary.

In October, 2013 after regular following with laboratorial exams and prescription of Itraconazole, the patient returned and we realised in physical examination that the big lesion of right leg had suffered carcinomatous degeneration, we saw verrucous plaques with blackened spots in surface and exudation area, measuring $20 \times 15$ centimetres. We requested a biopsy. Biopsy showed well differentiated infiltrating squamous cell carcinoma (Fig. 5). Immediately, the patient was forwarded to a cancer treatment center to remove it by surgery.

In April 2014, the patient performed right leg amputation surgery, at the level of the right knee. On the same occasion, a biopsy of the right thigh was done and it showed epidermis with orthokeratosis, psoriasiform pattern, with enlarged and fused cones on the dermis and basophilic degeneration of collagen fibers. Inflammatory infiltrate with lymphocytes and numerous plasma cells around the superficial blood capillaries were also found, concluding that it was a superficial or deep chronic dermatitis, perivascular, with rich plasma cells. Itraconazole $200 \mathrm{mg} /$ day was maintained after surgery. Some time later, he brought us the histopathology of the surgical specimen, that showed ulcerated squamous cell carcinoma, measuring $17 \mathrm{~cm}$ on its largest axis, infiltrating into the subcutaneous tissue, with lymph node and neural invasion detected, neoplastic free bone tissue and free surgical margins. Metastases to 1 of the 7 lymph nodes studied was detected.
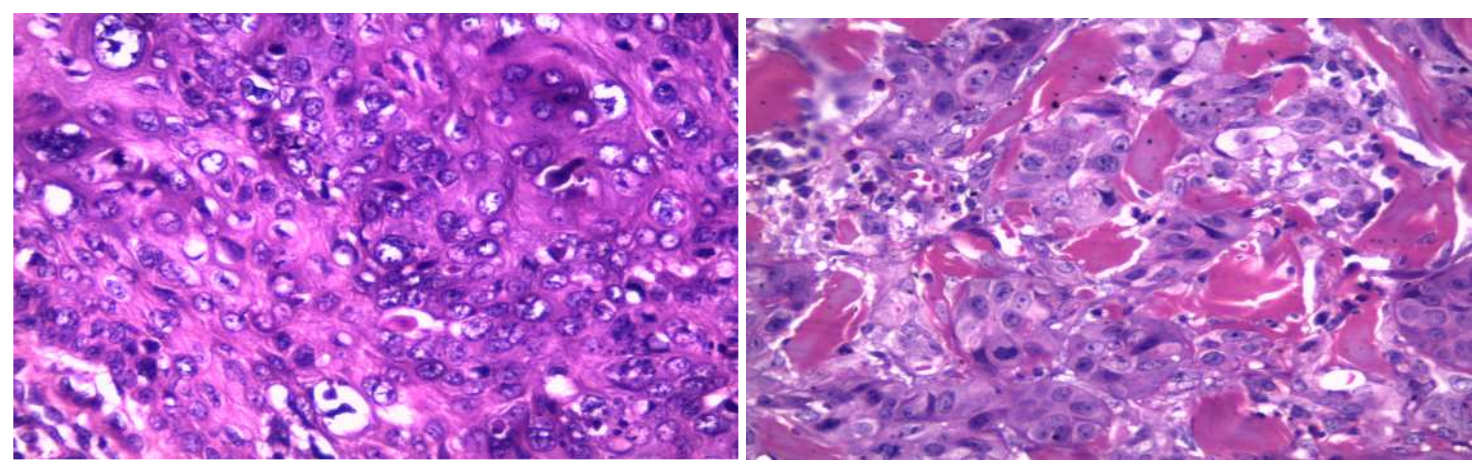

Fig. 5: Histopathological showing differentiated infiltrating squamous cell carcinoma

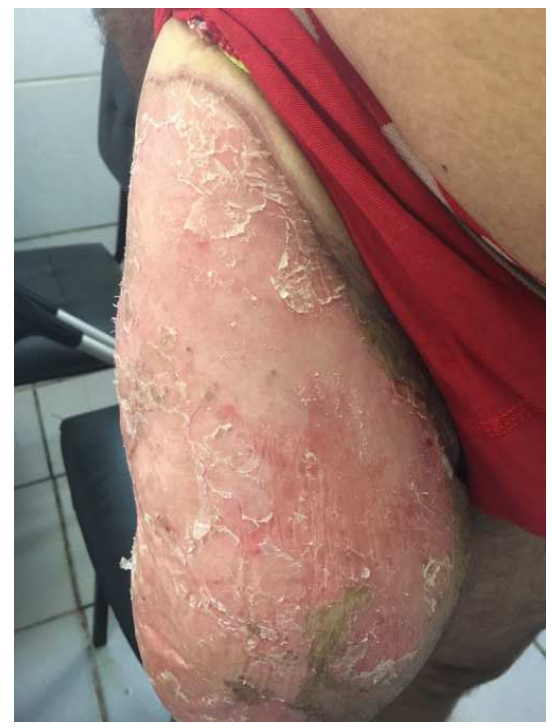

Fig. 6: Stump of the leg, showing chromomycosis lesions 
After that, patient returned to regular follow up of the left leg and right thigh (in leg stump) lesions (Fig. 6) and new biopsies were done regularly showing no more carcinomatosis. In October of 2015 he referred that lesions were growing fast, so we doubled Itraconazole dose and he started to take $400 \mathrm{mg} /$ day. In June of 2016 lesions were erythematous-scaly plaques with lamellar scales and irregular contours, measuring $28.5 \times 27$ centiemtres in the right thigh. In the left leg, plaque lesion with residual hypochromia and atrophy, measuring 26 centimetres in the largest diameter on the anterior side of the leg. In this month, patient referred inguinal pain on right side. Two lymph nodes were detected both in physical examination and ultrasonography and patient were forwarded to oncologist to evaluate it.

\section{Discussion}

Chromomycosis, or chromomycosis, is a chronic, progressive cutaneous and subcutaneous mycosis caused by several species of pheoid or dermaticeous (darkly pigmented) fungi (Lupi et al., 2005; Queiroz-Telles et al., 2011; Torres-Guerrero et al., 2012). It mainly affects male patients, in the age group between 30 and 60 years and is more common on rural areas, being associated to traumatic events, which may explain the high frequency of involvement of the lower limbs and exposed areas (Queiroz-Telles, 2015; Queiroz-Telles et al., 2011; Torres-Guerrero et al., 2012).

Chromomycosis lesion starts as a small, nonpruriginous, erythematous papule or macula and slowly spreads to the surrounding skin (Queiroz-Telles, 2015; Torres-Guerrero et al., 2012). Commonly, takes 5 to 15 years or more from the onset to diagnosis the disease (Torres-Guerrero et al., 2012). It happens because it takes months or years to new lesions develop on the same area or over adjacent areas (Torres-Guerrero et al., 2012). This means that the age distribution range does not necessarily coincide with the period of infection, once the beginning of the lesion is reported to be occurred years before (Silva, et al., 1998).

The disease lesions progress and evolve to variable morphology types, including nodular, verrucous or vegetant (cauliflower-like or craterlike), tumoral, cicatricial and lymphagitic (sporotrichoid) forms (Queiroz-Telles, 2015; Torres-Guerrero et al., 2012). Mixed lesions can be observed in the same patient (Queiroz-Telles, 2015; Torres-Guerrero et al., 2012). Despite of usually asymptomatic, it can be pruritic and painful over time, being ulcers and secondary infection a frequent complication (Queiroz-Telles, 2015; TorresGuerrero et al., 2012). Healed lesions can be present with scars, atrophic and achromic areas (Torres-Guerrero et al., 2012). Squamous cell carcinoma is reported to develop in chronic chromomycosis lesions (Queiroz-Telles, 2015; Lupi et al., 2005; Torres-Guerrero et al., 2012). The disease progress and complications can lead to definitive disability, especially due to treatment limitations (Queiroz-Telles, 2015; Lupi et al., 2005; TorresGuerrero et al., 2012).

In our cases, chromomycosis lesions evolved to an extensive polymorphic plaque and to disfiguring lesions, being an exuberant form of the disease. The epidemiology was characteristic; both were man and rural work, one of them reported a traumatic injury and the age of diagnostic was in the range of 30 and 60 years and coincidently the age of probably infection too. It is possible that patients only look for a health service when the lesions are too extensive, disfiguring, pruritic, painful or discharging pus due to a secondary infection, delaying diagnosis and treatment. Some patients report the use of alternatives "homeopathic" therapies, like teas and wood-extracted oils (Pires et al., 2012).

In Brazil, the Amazon region is considered to have the association of climatic conditions with underdeveloped regions that contributes for a high frequency of fungus infection, including chromomycosis (Silva, et al., 1998). The State of Pará was considered a major focus of the disease with 325 cases reported in 55 years and 65 cases in 7 years (Pires et al., 2012; Silva, et al., 1998). The rural activity associated to an improper care and protection equipment, common in undeveloped regions, may be a risk factor (Queiroz-Telles, 2015; Queiroz-Telles et al., 2011; Silva, et al., 1998). Other risk factors that have been proposed are poor nutrition and cultural and hygienic habits (Queiroz-Telles, 2015; Queiroz-Telles et al., 2011).

Chromomycosis treatment is a clinical and financial challenge, a number of antifungals drugs, isolated and combined, plus cryosurgery and surgery have been proposed as treatment in two trial and some case reports (Queiroz-Telles, 2015; Lupi et al., 2005; Torres-Guerrero et al., 2012; Alexandro et al., 1997; Gupta et al., 2002; Ranawaka et al., 2009). In most cases the treatment is difficult, probably because it requires a long period of following and maintenance of the drugs due to fungus' poor response and drugs' side effects. Also, in Brazil, drugs like amphotericin B and 5fluocytosine needs hospitalization and are very expensive as well as the others antifungals drugs (Brasil da, 2016).

In our cases, patients complained about the drug price and one of them abandoned treatment and medical follow up. The minimum wage in Brazil is $\mathrm{R} \$ 880,00$ (approximately \$270/month, \$9/8hours-day, \$1.12/hour) (Brasil, 2015), the cheaper Itraconazole in a $200 \mathrm{mg}$ /day dosage can cost between $\mathrm{R} \$ 184.28$ and $\mathrm{R} \$ 254.76$ (\$56.35-\$77.90) (Brasil da, 2016). It is available on the public health system but usually cannot supply the demand and is lacking in health care unit. Most patients cannot afford the treatment. Also, most patients come from rural areas, so their access to health services is impaired (Pires et al., 2012). One of the patients complained about the absence of medication and reported financial difficulties for transportation. These distance and difficulties may delay the diagnosis and 
impair the treatment, so, they must be mentioned and discussed by health professionals (Pires et al., 2012).

The chromomycosis histopathology often shows lymphoplasmocytic infiltration, microabscesses, suppurative or tuberculoid granuloma, multinucleated giant cells, neutrophils, eosinophils and macrophages (TorresGuerrero et al., 2012; Pradhan et al., 2017; Bonifaz et al., 2001). Observation of pseudoepitheliomatous hyperplasia and paraketosis, epithelial hyperplasia, epithelioid granuloma and transepithelial elimination of fungal cells are not rare (Torres-Guerrero et al., 2012; Pradhan et al., 2017; El-Khoury et al., 2012). Muriform cells can be found alone or in clusters, within or outside multinucleated giant cells and without special stains due to their naturally pigmented brown colour (Torres-Guerrero et al., 2012; Bonifaz et al., 2001). It can be identified in $\mathrm{H}$ and $\mathrm{E}$, or even in "unstained" and "de stained" sections for rapid screening or as substitute for special stains (Chavan et al., 2010).

Pseudoepitheliomatous or pseudocarcinomatous hyperplasia is usually found in deep fungal infections, as chromomycosis, associated to intraepidermal abscesses and granulomatous dermal inflammation (El-Khoury et al., 2012). It is believed that this epithelial proliferation is a reactive response to skin damage, which would act in transepithelial elimination of the foreign body material, explaining these founds in histopathology (El-Khoury et al., 2012). However, this proliferation can also be found in response to a wide variety of stimuli as neoplasms, inflammatory conditions and other infections. Its differentiation from welldifferentiated squamous cell carcinoma is difficult, especially in superficial biopsies, where it is also possible to have an associated basal cell carcinoma (El-Khoury et al., 2012; Tuttle et al., 2009).

Histopathology is important for diagnosis and confirmation of chromomycosis, especially in nodular and ulcerative cases. Misdiagnosis with squamous cell carcinoma and cutaneous tuberculosis is not rare (Bonifaz et al., 2001; Jakopp et al., 2013; Bandyopadhyay et al., 2015). Furthermore, it is essential to carefully follow chronic lesions due to the risk of squamous cell carcinoma development (Queiroz-Telles, 2015; Lupi et al., 2005; Torres-Guerrero et al., 2012). The presence of pseudoepitheliomatous hyperplasia may increase the chances of atypia development, due to the rapid and repeatedly proliferation, in addition to the chronic excessive inflammatory process, which may have some impact on carcinogenesis (Conceição et al., 2001).

The main limitation of our study included the difficulty to contact the patients of the case reports, they all lived in rural areas, far away from our research center and with poor cell phone sign.

\section{Conclusion}

In conclusion, clinicians, dermatologists and pathologists must be aware of chromomycosis as a possible diagnosis when considering a chronic skin condition. Also, early diagnosis and early appropriate therapy should be stimulated to improve patients' quality of live and prevent severe complications and morbidities. The expansion of rural health projects may be an interesting tool to diagnose earlier and improve the prognostic of this disease, given that in tropical developing countries, rural health is a big problem. Although not common, prevention strategies and alternative therapies should be investigated to improve chromomycosis management.

\section{Acknowledgement}

The authors want to thank MD. Maraya de Jesus Semblano Bittencourt for the help with histopathological reports.

\section{Author's Contributions}

Carla Andréa Avelar Pires: Took part in conception, design and revision of the study.

Aline de Lima Dias: Responsible for acquisition of data.

Adriana Kamilly Leitão Pitman Machado: Responsible for acquisition of data.

Manuela Nascimento de Lemos: Drafted the manuscript.

Walter Refkalefsky Loureiro: Drafted the manuscript.

Francisca Regina Oliveira Carneiro: Revised the manuscript critically.

\section{Compliance with Ethical Standards}

Funding: The authors declare that they have received no funds.

Conflicts of Interest: The authors declare that they have no conflict of interest.

Ethical Approval: All procedures performed in studies involving human participants were in accordance with the ethical standards of the Universidade do Estado do Pará ethic committee and with the 1964 Helsinki declaration and its later amendments or comparable ethical standards.

Informed Consent: Informed consent was obtained from all individual participants included in the study. Additional informed consent was obtained from all individual participants for whom identifying information is included in this article.

\section{References}

Alexandro, B., E. Martinez-Soto, E. Carrasco-Gerard and J. Peniche, 1997. Treatment of chromoblastomycosis with itraconazole, cryosurgery and a combination of both. Int. J. Dermatol., 36: 542-547. DOI: 10.1046/j.1365-4362.1997.00085.x 
Attapattu, M.C., 1997. Chromomycosis-a clinical and mycological study of 71 cases from Sri Lanka. Mycopathologia, 137: 145-51. PMID: 9368408

Bandyopadhyay, A., M. Kaushik, G. Mimi and B. Sabyasachi, 2015. Cutaneous chromoblastomycosis mimicking tuberculosis verrucosa cutis: look for copper pennies. Turk. Patoloji. Derg., 31: 223-5. DOI: $10.5146 /$ tjpath.2013.01197

Bonifaz, A., E. Carrasco-Gerard and A. Saul, 2001. Chromomycosis: clinical and mycologic experience of 51 cases. Mycoses, 44: 1-7. PMID: 11398635

Brasil da, S.M., 2016. Preços máximos de medicamentos por princípio ativo. In: Listas de preços de medicamentos. Agência Nacional de Vigilância Sanitária. http://portal.anvisa.gov.br/listas-de-precos

Brasil, 2015. Casa Civil da Presidência da República. Decreto $N^{\circ} 8.618$, de 29 de dezembro de 2015. Diário Oficial da União-Seção 1. Imprensa Nacional.

Chavan, S.S., M.H. Kulkarni and J.H. Makannavar, 2010. 'Unstained' and 'de stained' sections in the diagnosis of chromoblastomycosis: A clinicopathological study. Indian J. Pathol. Microbiol., 53: 666-671. DOI: 10.4103/0377-4929.72021

Conceição, M.P.S., S. Azevedo, G. Marques, W.C.L. Daniel and R. Raimunda et al., 2001. ResendeStoianoff Squamous cell carcinoma derived from chronic chromoblastomycosis in Brazil. Clin. Infect. Dis., 60: 1500-4. DOI: 10.1093/cid/civ104

Deng, S., C.K.M. Tsui, E.A.H.G. Gerrits van den, L. Yang and M.J. Najafzadeh et al., 2015. Global spread of human chromoblastomycosis is driven by recombinant cladophialophora carrionii and predominantly clonal fonsecaea species. PLoS Negl Trop. Dis., 9: e0004004. DOI: 10.1371/journal.pntd.0004004

El-Khoury, J., K. Abdul-Ghani and A. Ossama, 2012. Mucocutaneous pseudoepitheliomatous hyperplasia: a review. Am. J. Dermatopathol., 34: 165-75. DOI: 10.1097/DAD.0b013e31821816ab

Esterre, P., A. Andriantsimahavandy and C. Raharisolo, 1997. Natural history of chromoblastomycosis in madagascar and the indian ocean. Bull. Soc. Pathol. Exot., 90: 312-7. PMID: 9507759

Gupta, A.K., P.R. Taborda and A.D. Sanzovo, 2002. Alternate week and combination itraconazole and terbinafine therapy for chromoblastomycosis caused by Fonsecaea pedrosoi in Brazil. Med. Mycol., 40: 529-34. PMID: 12462534

Jakopp, B.B., D. Stamm and E.A. Conen, 2013. Hidden under a Cauliflower-Like Skin Tumor: Chromoblastomycosis. Case Reports Infect. Dis., 2013: 1-3. DOI: $10.1155 / 2013 / 450153$
Krzyściak, P.M., M. Pindycka-Piaszczyńska and M. Piaszczyński, 2014. Chromomycosis. Advances in Dermatology and Allergology/Postępy Dermatol. i Alergol., 5: 310.

Lupi, O., S.K. Tyring and M.R. McGinnis, 2005. Tropical dermatology: fungal tropical disease. J. Am. Acad. Dermatol., 53: 931-951. DOI: $10.1016 /$ j.jaad.2004.10.883

Minotto, R., C.D. Bernardi, L.F. Mallmann, M.I. Edelweiss and M.L. Scroferneker, 2001. Chromoblastomycosis: A review of 100 cases in the state of Rio Grande do Sul, Brazil. J. Am. Acad. Dermatol., 44: 585-92. PMID: 11260530

Pe'Rez-Blanco, M., R.H.N. Valles, G.F.N. Zeppenfeldt and R. Apitz-Castro, 2003. Ajoene and 5fluorouracil in the topical treatment of Cladophialophora carrionii chromoblastomycosis in humans: A comparative open study. Med. Mycol., 41: 517-520.

DOI: $10.1080 / 13693780310001616519$

Pindycka-Piaszczyńska, M., P. Krzyściak, M. Piaszczyński, S. Cieślik and T. Jagielski et al., 2014. Chromoblastomycosis as an endemic disease in temperate Europe: First confirmed case and review of the literature. Eur. J. Clin. Microbiol. Infect. Dis., 33: 391-398. DOI: 10.1007/s10096-013-1969-7

Pires, C.A.A., M.B. Xavier, J.A.S. Quaresma, G.M.M. de Macedo and B.R. Sousa et al., 2012. Clinical, epidemiological and mycological report on 65 patients from the Eastern Amazon region with chromoblastomycosis. An. Bras. Dermatol., 87: 555-560.

DOI: $10.1590 / \mathrm{S} 0365-05962012000400006$

Pradhan, S.V., O.P. Talwar, A. Ghosh, R.M. Swami and R. Shiva et al., 2017. Chromoblastomycosis in Nepal: A study of 13 cases. Indian J. Dermatol. Venereol. Leprol., 73: 176-178. DOI: 10.4103/0378-6323.32741

Queiroz-Telles, F., 2015. Chromoblastomycosis: A neglected tropical disease. Rev. Inst. Med. Trop. São. Paulo., 57: 46-50.

DOI: 10.1590/S0036-46652015000700009

Queiroz-Telles, F., M. Nucci, A.L. Colombo, A. Tobón and A. Restrepo, 2011. Mycoses of implantation in Latin America: An overview of epidemiology, clinical manifestations, diagnosis and treatment. Med. Mycol., 49: 225-236.

DOI: $10.3109 / 13693786.2010 .539631$

Ranawaka, R.R., N. Amarasinghe and D. Hewage, 2009. Chromomycosis: Combined treatment with pulsed itraconazole therapy and liquid nitrogen cryotherapy. Int. J. Dermatol., 48: 397-400.

DOI: $10.1111 /$ j.1365-4632.2009.03744.x 
Silva, J.P., W. de Souza and S. Rozental, 1998. Chromoblastomycosis: A retrospective study of 325 cases on Amazonic Region (Brazil). Mycopathologia, 143: 171-175.

DOI: $10.1023 / \mathrm{A}: 1006957415346$

Torres-Guerrero, E., R. Isa-Isa, M. Isa and R. Arenas, 2012. Chromoblastomycosis. Clin. Dermatol., 30: 403-408. DOI: 10.1016/j.clindermatol.2011.09.011
Tuttle, M.S., A.S. Rosenberg, H.L. Winfield and S.C. Somach, 2009. Pseudocarcinomatous hyperplasia with follicular differentiation overlying basal cell carcinoma. Am. J. Dermatopathol., 31: 557-560. DOI: 10.1097/DAD.0b013e3181a5e7b4 